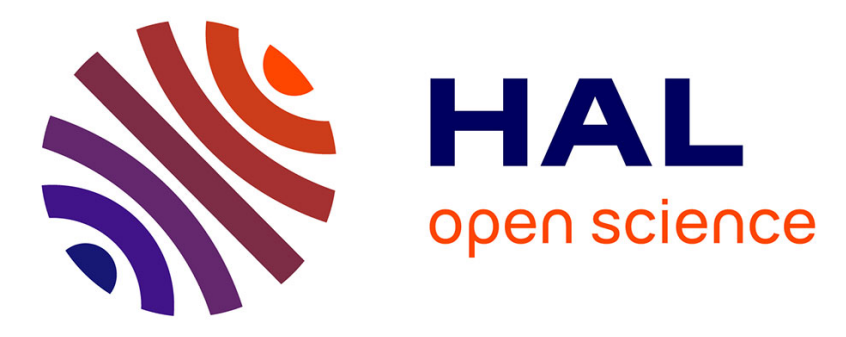

\title{
Predicting visual success in macular hole surgery
}

Bhaskar Gupta, David A Laidlaw, Shaheen Shah, Roger Wong, Siobhan Wren

\section{To cite this version:}

Bhaskar Gupta, David A Laidlaw, Shaheen Shah, Roger Wong, Siobhan Wren. Predicting visual success in macular hole surgery. British Journal of Ophthalmology, 2009, 93 (11), pp.1488-n/a. 10.1136/bjo.2008.153189 . hal-00477834

\section{HAL Id: hal-00477834 \\ https://hal.science/hal-00477834}

Submitted on 30 Apr 2010

HAL is a multi-disciplinary open access archive for the deposit and dissemination of scientific research documents, whether they are published or not. The documents may come from teaching and research institutions in France or abroad, or from public or private research centers.
L'archive ouverte pluridisciplinaire $\mathbf{H A L}$, est destinée au dépôt et à la diffusion de documents scientifiques de niveau recherche, publiés ou non, émanant des établissements d'enseignement et de recherche français ou étrangers, des laboratoires publics ou privés. 
Title: Predicting visual success in macular hole surgery

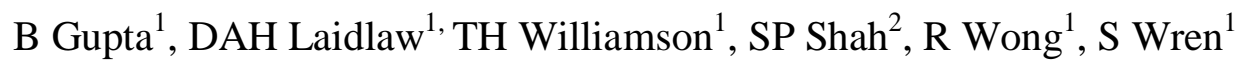

${ }^{1}$ Department of Ophthalmology, St. Thomas's Hospital, Lambeth Palace Road

London SE1 7EH, UK

${ }^{2}$ International Centre for Eye Health, Clinical Research Unit, London School of Hygiene and Tropical Medicine, Keppel St, London WC1E 7HT

Correspondence to:

Mr. DAH Laidlaw

Department of Ophthalmology, St. Thomas Hospital, Lambeth Palace Road

London SE1 7EH, UK

Alistair.Laidlaw@gstt.nhs.uk

Phone : +442071887188

Fax : +442071884312

Proprietary Interest: None

The authors have no competing Interest

The Corresponding Author has the right to grant on behalf of all authors and

does grant on behalf of all authors, an exclusive licence (or non exclusive

for government employees) on a worldwide basis to the BMJ Publishing Group Ltd

to permit this article (if accepted) to be published in $\mathrm{BJO}$ and any other

BMJPGL products and sublicences such use and exploit all subsidiary rights, as

set out in their licence 


\section{Abstract}

\section{Title: Predicting visual success in macular hole surgery}

\section{Introduction}

Surgical outcome data facilitate informed pre operative patient counseling. Most studies to date on the outcome of surgery for idiopathic full thickness macular hole (IFTMH) surgery have tended to concentrate on rates of anatomical closure. The aim of this study was to investigate for factors predicting visual success (better than 20/40; 6/12 Snellen) following macular hole surgery.

\section{Methods}

A retrospective study of 133 patients undergoing standardised macular hole surgery with at least 3 months of post operative follow up. All patients underwent pre operative measurement of the maximum macular hole diameter using optical coherence tomography.

\section{Results}

Multivariable regression analysis identified that age, pre operative visual acuity and macular hole size were significant predictors of visual success. The resulting model correctly classified the visual outcome of $80 \%$ of cases. Predicted rates of visual success varied from $93 \%$ in patients $<60$ years with acuity better than $6 / 24$ and a hole diameter of $<350$ microns to $2 \%$ in patients those $>79$ years with acuity of $6 / 60$ or worse and hole diameter of $>500$ microns.

\section{Conclusion}

The results provide a simple and clinically useful model to employ when counseling patients regarding macular hole surgery. 


\section{Introduction}

Surgical outcome data facilitates informed pre operative patient counseling. To date most data on the outcome of idiopathic full thickness macular hole (IFTMH) surgery have concentrated on technique and rates of anatomical closure ${ }^{1-6}$. The aim of this study was to investigate factors predicting restoration of good visual acuity (better than 20/40; 6/12 UK Snellen) and to present these data in a clinically usable format to use in pre operative counseling. As surgical techniques are known to differ widely ${ }^{7-9}$ in building the cohort we only included patients that had the same surgical technique and post operative instructions, making this study one of the largest cohorts of patients undergoing standardized macular hole surgery.

\section{Methods}

A retrospective case note review of all phakic patients undergoing surgery for IFTMH under one consultant led surgical team from March 2004 until October 2007 was performed. Local ethics committee approval was obtained. Only the first operation on the first operated eye of each patient was included in the analysis. Exclusion criteria included macular holes in association with trauma, any previous intraocular surgery and a history of other vision limiting eye conditions such as age related macular degeneration, glaucoma and amblyopia.

Data collected included: age, sex, laterality, duration of visual symptoms, pre-operative visual acuity (VA), pre operative maximum minimum linear diameter (MLD), grade of operating surgeon, intra and post-operative complications, post-operative anatomical closure and VA at three months. (Table: 1 ).

Pre operative MLD of the IFTMH was measured using optical coherence tomography (OCT) (Stratus OCT ${ }^{\mathrm{TM}}$, Zeiss and Topcon 3D OCT-1000) and was defined as the greatest linear distance along the smallest hole aperture (figure 1). 
All cases underwent phacoemulsification and intraocular lens implantation followed by 20 gauge three port pars plana vitrectomy (PPV) with induction of a posterior vitreous detachment when not already present. Indocyanine green (ICG) assisted internal limiting membrane peeling was performed in all cases using $0.5 \mathrm{ml}$ of $0.5 \mathrm{mg} / \mathrm{ml}(0.05 \%)$ ICG and minimal retinal exposure time followed by fluid to air to $16 \% \mathrm{C}_{3} \mathrm{~F}_{8}$ gas exchange. All patients were instructed to maintain an upright post operative posture during the day and to strictly avoid sleeping in a supine position. Follow-up was performed at day 1,2 weeks and 3 months. Anatomical closure was determined at 3 months after surgery using indirect slit lamp biomicroscopy.

\section{Statistical Analysis}

Snellen acuities were converted to $\log$ MAR units for analysis. LogMAR values of 2.0 and 3.0 were used for vision of counting finger (CF) and hand movement (HM) respectively. Distribution analysis revealed post operative vision and MLD to be non normally distributed. In order to make prediction probabilities easier for application in a clinical setting a binary outcome variable "visual success' was defined, consistent with previous literature ${ }^{10}$, as post operative VA of $<0.3 \log$ MAR (better than 6/12) at 3 months. MLD was categorized into quartiles ( $<350, \geq 350$ to $<400, \geq 400$ to $<500, \geq 500$ microns), age into decades and pre operation visual acuity as $\geq 0.3$ to $<0.6, \geq 0.6$ to $<0.9$ and $\geq 0.9 \log$ MAR. Logistic regression analysis was used to determine which explanatory variables were to be included in the predictor for visual success. The multivariable model was built using a forward manual stepwise method by adding the most significant variable first. The significance level for removal from the model was $\mathrm{p}=0.1$. Odds ratios $(\mathrm{OR})$ and $95 \%$ confidence intervals $(95 \% \mathrm{CI})$ are derived from this model. All $\mathrm{p}$ values are two sided. Prediction models using logistic regression are evaluated by establishing a cutoff point; predicted probabilities below the cutoff point are treated as predictors of no event and predictions at or above the cutoff point are considered to be

predictors of the event. ${ }^{11}$ A cutoff point of 0.50 is usually chosen. Using the 0.5 prediction cutoff points, we calculated the proportion of patients correctly classified by the model. The proportion of correct predictions is the proportion of patients in the total sample whose observed status (visual success) agreed with their predicted vital status. The predictive ability of the final model was assessed in three ways. First, receiver-operating characteristic (ROC) curves were calculated, second, the McNemar test was used to compare the percentages of correct predictions (see below) and thirdly, goodness of fit was assessed using the Hosmer-Lemeshow test. ${ }^{12}$ 


\section{Results}

Of the 132 eyes (of 132 subjects) 96 were women (72.7\%). Demographic distribution is shown on Table 1. The overall anatomical closure rate was $86 \%(113 / 132)$. Median visual acuity improvement was $0.39 \log$ MAR (IQR: 0.16, 0.6), with 33\% (44/132) achieving visual success of better than 20/40.

Table 1: Demographics of patients

\begin{tabular}{|l|l|r|r|r|r|r|r|r|r|}
\hline & & Obs. & Mean & Std. & median & IQR & & \multicolumn{1}{l|}{ Min } & \multicolumn{1}{l|}{ Max } \\
\hline Age & Years & 132 & 67.83 & 7.55 & 67.5 & 63 & 73 & 51 & 85 \\
\hline Symptoms & Months & 132 & 12.02 & 18.83 & 6.5 & 3 & 12 & 1 & 99 \\
\hline Pre-op VA & LogMAR & 132 & 0.82 & 0.32 & 0.78 & 0.6 & 1 & 0.3 & 2 \\
\hline Hole diameter & Microns & 128 & 426.28 & 141.69 & 406 & 345 & 500 & 174 & 810 \\
\hline Post-op VA & LogMAR & 132 & 0.50 & 0.50 & 0.3 & 0.18 & 0.6 & -0.1 & 3 \\
\hline & & & & & & & & & \\
\hline Gender & Women & 96 & $72.70 \%$ & & & & & & \\
\hline Laterality * & right & 84 & $63.60 \%$ & & & & & & \\
\hline Operator* & Consultant & 77 & $58.30 \%$ & & & & & & \\
\hline Visual success & $>6 / 12$ & 44 & $33.30 \%$ & & & & & & \\
\hline
\end{tabular}

Univariable analysis suggested that anatomical closure $(\mathrm{p}=0.022)$, decreasing hole size $(\mathrm{p}<0.001)$, better pre op visual acuity $(\mathrm{p}<0.001)$ and younger age $(\mathrm{p}=0.002)$ were significantly associated with visual success (Table 2). Univariable and multivariable odds ratios for these explanatory variables are shown in Table 2. A highly significant association of MLD and anatomical outcome was found (<350 microns $96.6 \%$ anatomical closure; $\geq 350$ to $<40089.7 \%$; $\geq 400$ to $<50087.5 \% ; \geq 50067.6 \%$ anatomical closure, $\mathrm{p}<0.001)$. This confounding factor, in the adjusted analysis was no longer statistically significant $(\mathrm{p}=0.1)$ and anatomical closure was therefore not included in the predictor equation. 
Table 2: Univariable and multivariable model of visual success (post-operative acuity better than 20/40; 6/12 Snellen)

\begin{tabular}{|c|c|c|c|c|c|c|c|c|}
\hline \multirow{3}{*}{$\begin{array}{l}\text { Hole size (Microns) } \\
<350\end{array}$} & \multicolumn{2}{|c|}{ Univariable } & & & \multirow{3}{*}{$\begin{array}{l}\mathrm{OR} \\
1\end{array}$} & \multicolumn{2}{|c|}{ Multivariable } & \\
\hline & \multirow{2}{*}{$\begin{array}{l}\mathrm{OR} \\
1\end{array}$} & \multirow[t]{2}{*}{$\mathrm{P}=$} & \multicolumn{2}{|c|}{$95 \% \mathrm{CI}$} & & \multirow[t]{2}{*}{$\mathrm{P}=$} & \multicolumn{2}{|c|}{$95 \% \mathrm{CI}$} \\
\hline & & & & & & & & \\
\hline$\geq 350$ to $<400$ & 0.28 & 0.02 & 0.1 & 0.82 & 0.41 & 0.14 & 0.12 & 1.35 \\
\hline$\geq 400$ to $<500$ & 0.29 & 0.018 & 0.1 & 0.81 & 0.41 & 0.13 & 0.13 & 1.28 \\
\hline$\geq 500$ & 0.1 & $<0.001$ & 0.03 & 0.34 & 0.19 & 0.02 & 0.05 & 0.76 \\
\hline \multicolumn{9}{|l|}{$\begin{array}{l}\text { Pre op VA (logMAR } \\
\text { equivalent) }\end{array}$} \\
\hline$\geq 20 / 40$ to $<20 / 80$ & 1 & & & & 1 & & & \\
\hline$\geq 20 / 80$ to $<20 / 160$ & 0.3 & 0.024 & 0.11 & 0.86 & 0.4 & 0.14 & 0.12 & 1.33 \\
\hline$\geq 20 / 160$ & 0.06 & $<0.001$ & 0.02 & 0.23 & 0.1 & 0.003 & 0.022 & 0.45 \\
\hline \multicolumn{9}{|l|}{ Age (Years) } \\
\hline $50-59$ & 1 & & & & 1 & & & \\
\hline $60-69$ & 0.33 & 0.04 & 0.11 & 0.96 & 0.25 & 0.045 & 0.07 & 0.97 \\
\hline 70-79 & 0.14 & 0.001 & 0.04 & 0.46 & 0.12 & 0.006 & 0.03 & 0.54 \\
\hline $80+$ & 0.15 & 0.04 & 0.02 & 0.89 & 0.07 & 0.017 & 0.01 & 0.63 \\
\hline Anatomical success & 11.1 & 0.022 & 1.42 & 85.8 & Dropp & & & \\
\hline
\end{tabular}

VA Visual acuity, OR Odds Ratio, CI Confidence Interval

Using the results of the multivariable analysis the probabilities of visual success are shown on Table 3. 
Table 3: Predicting probability (\%) of post operative visual success

\begin{tabular}{|c|c|c|c|c|c|c|c|c|c|c|c|c|}
\hline \multirow{2}{*}{$\begin{array}{l}\text { Age } \\
\text { group (Years) } \\
\text { Pre Op } \\
\text { VA* }^{*}\end{array}$} & \multicolumn{3}{|l|}{$50-59$} & \multicolumn{3}{|l|}{$60-69$} & \multicolumn{3}{|l|}{$70-79$} & \multicolumn{3}{|l|}{$80+$} \\
\hline & $\geq 0.6^{\star}$ & $\begin{array}{l}<0.6 \\
\text { to } \\
\geq 0.9\end{array}$ & $>0.9$ & $\geq 0.6^{*}$ & $\begin{array}{l}<0.6 \\
\text { to } \\
\geq 0.9\end{array}$ & $>0.9$ & $\geq 0.6^{\star}$ & $\begin{array}{l}<0.6 \\
\text { to } \\
\geq 0.9\end{array}$ & $>0.9$ & $\geq 0.6^{*}$ & $\begin{array}{l}<0.6 \\
\text { to } \\
\geq 0.9\end{array}$ & $>0.9$ \\
\hline \multicolumn{13}{|l|}{ MLD ** } \\
\hline$<350$ & 93 & 84 & 56 & 76 & 57 & 25. & 60 & 38 & 13 & 49 & 28 & 9 \\
\hline$\geq 350$ to $<400$ & 84 & 68 & 34 & 57 & 35 & 12 & 39 & 20 & 6 & 28 & 14 & 4 \\
\hline$\geq 400$ to $<500$ & 84 & 68 & 34 & 57 & 35 & 12 & 38 & 20 & 6 & 28 & 13 & 4 \\
\hline$\geq 500$ & 71 & 49 & 19 & 51 & 21 & 6 & 22 & 10 & 3 & 15 & 7 & 2 \\
\hline
\end{tabular}

*VA Visual acuity, ** MLD Maximum Linear Dimension in microns

The multivariable model correctly classified outcome in $79.7 \%$ of cases. The ROC curve in Figure 2 shows an area under the curve of $82 \%$ (i.e. good accuracy) ${ }^{13}$. Finally, we evaluated the goodness of fit of the models by using the Hosmer-Lemeshow test, which yielded a $\mathrm{p}$ value of 0.623 , indicating that the model fits well

Anatomical closure was not achieved in 19 eyes. In 5/19 there was a $\geq 2$ line of logMAR worsening of the visual acuity. Major complications included 1 eye with unsuccessful closure developing peripapillary $\mathrm{CNV}$ and associated pigment epithelial detachment and another developing retinal detachment requiring repeat surgery with silicone oil. 


\section{Discussion}

A third of patients in this series of standardized surgeries for IFTMH attained visual success of better than 20/40 Snellen. There are many different thresholds for visual success defined for macular hole surgery including mean number of Snellen lines gained ${ }^{14 ; 15}$ and proportions of

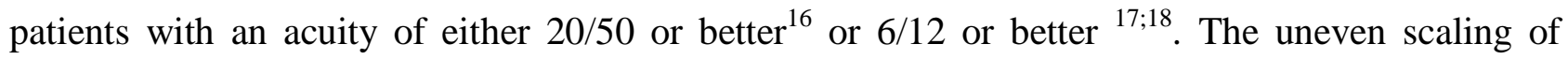
Snellen charts renders the former measure inappropriate. The absence of a 20/50 (6/15) line on most UK Snellen charts precludes the latter. We selected an acuity of better than $6 / 12$ to avoid the rounding up errors of 6/12 'part' being accorded a clinic acuity of 20/40. The overall anatomical closure rate in this study was $86 \%$ with $1 / 3$ of patients achieving an acuity of better than 20/40 Snellen. These results from a training institution are broadly comparable to those reported by others for combined cataract and macular hole surgery: in such series rates of anatomical success range from $92 \%$ to $100 \%{ }^{19-21}$ respectively with $20 \%$ achieving $>6 / 12^{22}$, improvement of $2-5.7$ lines from baseline ${ }^{23 ; 24}$

We are not aware of any other studies which have similarly modeled visual success in order to produce a simple probability chart. Visual outcome has been previously shown to be correlated with macular hole diameter ${ }^{25}$ but that study did not allow prediction of visual outcome.

Our mathematical model of visual success (better than 20/40;6/12 Snellen) is easy to apply clinically as it is based on 3 standard clinical measurements: age, visual acuity and OCT hole maximum minimum linear dimension (table 3). The predicted range of visual success varies from $2 \%$ in patients over 80 years of age with large holes and a presenting acuity of 6/60 or worse to $93 \%$ in subjects under 60 years of age with a presenting acuity of 20/80 or better and a hole of $<350$ microns MLD. The model appears to be an accurate predictor of outcome, with an area under the ROC curve of $82 \%$ and $80 \%$ of observed cases being correctly classified.

There are a number of caveats that should be considered before widely generalizing our results. The surgeries conducted here were of a standardized format (i.e. combined phaco-vitrectomy, ICG assisted internal limiting membrane peeling and no prone posturing) accordingly the model may not be applicable in other circumstances. It has been suggested that ICG toxicity may adversely affect visual outcome, we are not however aware of any evidence of such toxicity when a concentration of $0.5 \mathrm{mg} / \mathrm{ml}$ has been employed. It has recently been shown that five days of 8 hours per day prone posturing results in an improved rate of anatomical closure in patients with holes of 400 microns or 
greater MLD. ${ }^{26}$ None of the patients in this study underwent post operative prone posturing. In holes of up to 400 microns our anatomical closure rate was $93 \%$ with visual success rates of $42 \%$ and for holes greater than 400 microns our results were $77 \%$ and $20 \%$ respectively. Accordingly the proportion of patients achieving visual success might have been higher had such prone posturing been advocated for patients with holes larger than 400 microns. Continued visual improvement has been observed in patients with successful macular hole repair beyond 1 year postoperatively ${ }^{27}$; our relatively short follow up time (3 months) must be noted. We have also retrospectively analyzed clinic Snellen acuities measured by a variety of technicians rather than best corrected $\log$ MAR results. The statistical validity of the model suggests robustness, however a prospective study to formal validate and test the accuracy of the predicted probabilities is required. Lastly biometric factors $^{28}$ have been associated with FTMH and inclusion of this data may have improved the model.

\section{Conclusion}

The data presented in this paper may facilitate pre operative patient counseling about the likely visual outcome of macular hole surgery. This novel predictor is easy to use and can provide the patient with guiding information when debating whether to undertake FTMH surgery. The limitations of the predictor must however also be taken into account when providing guidance. 
$\underline{\text { Reference List }}$

1. Al-Abdulla NA, Thompson JT, Sjaarda RN. Results of macular hole surgery with and without epiretinal dissection or internal limiting membrane removal. Ophthalmology 2004;111:142$\underline{9 .}$

2. Beutel J, Dahmen G, Ziegler A et al. Internal limiting membrane peeling with indocyanine green or trypan blue in macular hole surgery: a randomized trial. Arch. Ophthalmol. 2007; 125:326-32.

3. Dhawahir-Scala FE, Maino A, Saha K et al. To posture or not to posture after macular hole surgery. Retina 2008;28:60-5.

4. Kwok AK, Lai TY, Yuen KS et al. Macular hole surgery with or without indocyanine green stained internal limiting membrane peeling. Clin.Experiment.Ophthalmol. 2003;31:470-5.

5. Madgula IM, Costen M. Functional outcome and patient preferences following combined phaco-vitrectomy for macular hole without prone posturing. Eye 2008;22:1050-3.

6. Merkur AB, Tuli R. Macular hole repair with limited nonsupine positioning. Retina 2007;27:365-9.

7. Kwok AK, Lai TY, Yuen KS et al. Macular hole surgery with or without indocyanine green stained internal limiting membrane peeling. Clin.Experiment.Ophthalmol. 2003;31:470-5. 
8. Al-Abdulla NA, Thompson JT, Sjaarda RN. Results of macular hole surgery with and without epiretinal dissection or internal limiting membrane removal. Ophthalmology 2004;111:142$\underline{9 .}$

9. Beutel J, Dahmen G, Ziegler A et al. Internal limiting membrane peeling with indocyanine green or trypan blue in macular hole surgery: a randomized trial. Arch.Ophthalmol. 2007; 125:326-32.

10. Jaycock PD, Bunce C, Xing W et al. Outcomes of macular hole surgery: implications for surgical management and clinical governance. Eye 2005;19:879-84.

11. Schuchter L, Schultz DJ, Synnestvedt M et al. A prognostic model for predicting 10-year survival in patients with primary melanoma. The Pigmented Lesion Group. Ann.Intern.Med. 1996;125:369-75.

12. Hosmer DW. Applied Logistic Regression. Lemeshow S. 1989. New York: Wiley. $\underline{\text { Ref Type: Generic }}$

13. Tape, T. G. Interpreting Diagnostic Tests. http://gim.unmc.edu/dxtests/ROC3.htm, university of Nebraska . 2008. $\underline{\text { Ref Type: Generic }}$

14. Dhawahir-Scala FE, Maino A, Saha K et al. To posture or not to posture after macular hole surgery. Retina 2008;28:60-5.

15. Madgula IM, Costen M. Functional outcome and patient preferences following combined phaco-vitrectomy for macular hole without prone posturing. Eye 2008;22:1050-3. 
16. Lai MM, Williams GA. Anatomical and visual outcomes of idiopathic macular hole surgery with internal limiting membrane removal using low-concentration indocyanine green. Retina 2007;27:477-82.

17. Jaycock PD, Bunce C, Xing W et al. Outcomes of macular hole surgery: implications for surgical management and clinical governance. Eye 2005;19:879-84.

18. Kang HK, Chang AA, Beaumont PE. The macular hole: report of an Australian surgical series and meta-analysis of the literature. Clin.Experiment.Ophthalmol. 2000;28:298-308.

19. Dhawahir-Scala FE, Maino A, Saha K et al. To posture or not to posture after macular hole surgery. Retina 2008;28:60-5.

20. Madgula IM, Costen M. Functional outcome and patient preferences following combined phaco-vitrectomy for macular hole without prone posturing. Eye 2008;22:1050-3.

21. Merkur AB, Tuli R. Macular hole repair with limited nonsupine positioning. Retina $\underline{2007 ; 27: 365-9 .}$

22. Dhawahir-Scala FE, Maino A, Saha K et al. To posture or not to posture after macular hole surgery. Retina 2008:28:60-5.

23. Madgula IM, Costen M. Functional outcome and patient preferences following combined phaco-vitrectomy for macular hole without prone posturing. Eye 2008;22:1050-3.

24. Merkur AB, Tuli R. Macular hole repair with limited nonsupine positioning. Retina $\underline{2007 ; 27: 365-9 .}$ 
25. Ruiz-Moreno JM, Staicu C, Pinero DP et al. Optical coherence tomography predictive factors for macular hole surgery outcome. Br.J.Ophthalmol. 2008;92:640-4.

26. Guillaubey A, Malvitte L, Lafontaine PO et al. Comparison of face-down and seated position after idiopathic macular hole surgery: a randomized clinical trial. Am.J.Ophthalmol. 2008;146:128-34.

27. Kumagai K, Furukawa M, Ogino N et al. Long-term outcomes of macular hole surgery with triamcinolone acetonide-assisted internal limiting membrane peeling. Retina 2007:27:1249$\underline{54 .}$

28. Shah SP, Laidlaw DA. Vitrectomy for diabetic macular edema. Am.J.Ophthalmol. 2006;141:225. 


\section{Legends To Figure}

Figure 1: Maximum Linear Diameter measured as the greatest linear distance along the smallest hole aperture(a-b)

Figure 2: ROC curve analysis of multivariable model. 


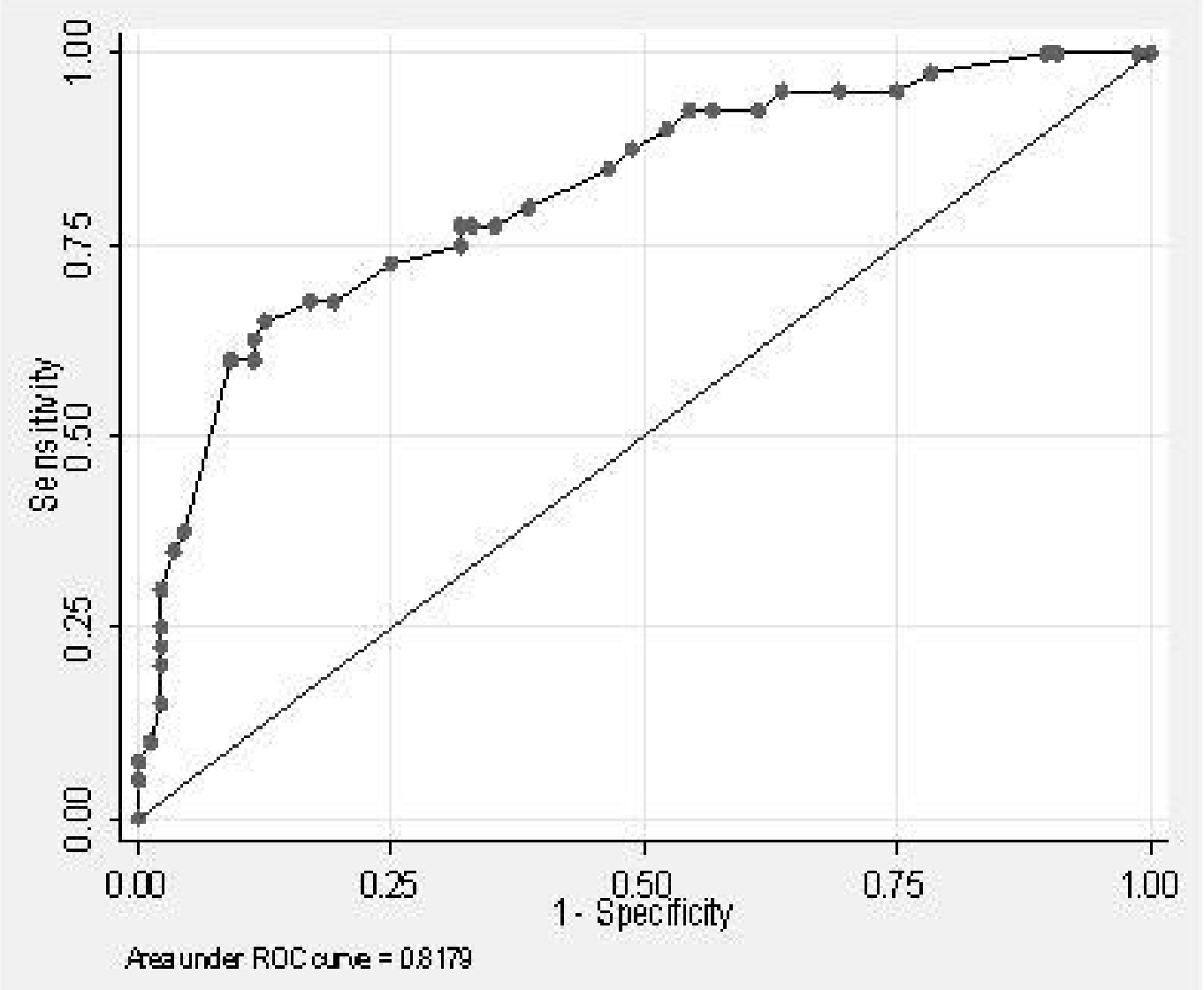

Figure 2: ROC curve analysis of multivariable model. 